\title{
Gap analysis on Research and Innovation for Cyber-Physical Systems in Manufacturing
}

\author{
Anna De Carolis*, Giacomo Tavola*, Marco Taisch* \\ *Politecnico di Milano, Via Lambruschini 4/b, 20156 Milano ITALY \\ anna.decarolis@polimi.it, giacomo.tavola@polimi.it, \\ marco.taischepolimi.it
}

\begin{abstract}
.
In defining the Roadmap of the Research Priorities for adoption of CPS in manufacturing industry, it is crucial to identify the key elements preventing a fast and smooth transition from the current status to the desired one. In such complex environments characterized by many industrial sectors and processes, external factors and social/economical influences, it is important to address only the main issues to achieve the result. This paper is aiming to illustrate the results of the Gap Analysis activities carried out in the sCorPiuS (http://scorpius-project.eu/) project.
\end{abstract}

Keywords: Cyber-Physical Systems, gap analysis, research roadmap, manufacturing industry

\section{Introduction}

Manufacturing is a key asset for Europe: it is a backbone for research, innovation, productivity, job and GDP creation and exports. De-Industrialization hit Europe, but EU initiatives decided since the beginning of the crisis are aiming to reverse the trend. Cyber-Physical Systems (CPS) are one of the key and most promising enabling technologies for the transformation of manufacturing companies towards the fourth industrial revolution (Wang, Törngren, \& Onori, 2015). In fact, their intrinsic potentialities allow them to obtain a relevant role for the digitalization of manufacturing environment, providing higher value essentially in three main dimension: smart product, smart manufacturing and changes in business models (Oettinger, 2015). Such opportunities are guaranteed by CPS' ability to integrate physical objects with computing, memorizing and communicating elements supported by actuators and connected each other via web. Several challenges need to be addressed in order to spread the adoption of CPS allowing to achieve major breakthroughs, both from the technical (i.e. security, human interaction, robust connectivity) and business perspectives. Additionally, specific types of Obstacles related with macro-dynamics (social, economic or technological) or with legal compliance have been found. For this reason, these breakthroughs and obstacles have been grouped in clusters defined in order to better scope and identify the potential

adfa, p. 1, 2011.

(C) Springer-Verlag Berlin Heidelberg 2011 
gaps existing which limit CPS implementation. These are the six main clusters identified (sCorPiuS State of the Art on Cyber-Physical Systems, 2016):

(1) New data-based services and business models; which refers to the CPS ability to open new business opportunities, allowing companies to be closer to customers' needs by offering them high customized and value added services;

(2) Data-based improved products; which allows companies to obtain feedback in real time from product usage and so to enhance them to create ad-hoc services and customized products thanks to the higher visibility level obtained;

(3) Closed-loop manufacturing; which affects also other stakeholders in the value network, such as suppliers and customers;

(4) Cyberized plant / "Plug \& Produce"; which allows companies to obtain a full flexibility and reconfigurability of the production environment and to facilitate operations management optimization;

(5) Next step production efficiency; which enables a better utilization of factory assets and so a more efficient production system;

(6) Digital ergonomics; which entails different consequences for workers, such as a faster knowledge transferring, the improvement of worker experience and of support at work and the operative complexity reduction.

This paper is aiming to illustrate the results of the gap analysis activities carried out in the sCorPiuS project in order to describe and to link breakthroughs coming from CPS implementation with the related obstacles that limit their adoption in manufacturing.

\section{$2 \quad$ Methodology}

This chapter describes the approach for analysis and identification of existing gaps. These gaps can be considered as the missing links between the strategic breakthroughs CPS adoption may bring into Manufacturing industry and the major obstacles to their achievement into the overall frame of the sCorPiuS vision (sCorPiuS Vision, 2016). The identification of the gaps is the result of the sequence of steps listed below carried out in the early sCorPiuS project phases:

1. Consolidation and validation of output from the State-of-the-Art analysis, Knowledge Capture Events and Experts' interviews;

2. Identification and definition of clusters collecting the main characteristics of breakthroughs and obstacles;

3. Identification, for each cluster, of some sub-clusters gathering breakthroughs and obstacles elements. The idea is to have a set of homogeneous groups of specific identified breakthroughs to match with specific subset of obstacles. In the crossing, it is identified the gap to overcome in order to remove the obstacle and achieve the envisaged result.

Crossing breakthrough and obstacle sub-clusters and selecting the most significant intersections will point out the researched gaps. 


\section{Gap analysis results}

\section{Cluster 1: New data-based services and business models}

Crossing the identified breakthrough sub-clusters with each obstacle sub-cluster, one main gap arises. CPS could generate new business opportunities driven by product sense systems and service-oriented business models, but their costs and benefits are currently not well evaluated and therefore the return on the investment (ROI) is still unknown and difficult to predict.

Table 1. New data-based services and business models - Gap

\begin{tabular}{|c|l|l|l|c|}
\hline \multicolumn{2}{|c|}{$\begin{array}{c}\text { Obstacles } \\
\text { New data-based services and business } \\
\text { models }\end{array}$} & $\begin{array}{l}\text { CPS embedded } \\
\text { complexity }\end{array}$ & $\begin{array}{l}\text { Need of guide- } \\
\text { lines and risk } \\
\text { of disillusion }\end{array}$ & $\begin{array}{l}\text { Uncertain ROI - } \\
\text { benefits and ob- } \\
\text { stacles not clear }\end{array}$ \\
\hline \multirow{4}{*}{$\begin{array}{l}\text { Active information and big data genera- } \\
\text { tion }\end{array}$} & & & \\
\cline { 2 - 5 } & $\begin{array}{l}\text { Customer driven responsive business } \\
\text { models }\end{array}$ & & & \\
\cline { 2 - 5 } & $\begin{array}{l}\text { Digital business ecosystems for sensing } \\
\text { products/services }\end{array}$ & & \\
\cline { 2 - 5 } & $\begin{array}{l}\text { Distributed collaboration - horizontal } \\
\text { and vertical integration }\end{array}$ & & \\
\cline { 2 - 5 } & Predictive management & & & \\
\cline { 2 - 5 } & Socio-economic changes & & \\
\hline
\end{tabular}

This obstacle mainly limits both the achievement of technical and technological innovative systems and potential results from new business opportunities.

\section{Cluster 2: Data-based improved products}

From the analysis carried out, it is possible to identify two main gaps that need to be further explored. The first one arises from the intersection between "Data-driven products use/maintenance (MoL)" and "Communication problems - smart products vs old factories". Embedding CPS in final products could simplify communication and information exchange among products and between factory and products. In this way, companies could have visibility on the way their products are used, give customers guidance and help in case of malfunctioning and also inform customers when preventive maintenance is needed. However, the main problem is that, although embedded products are relatively easy to produce, the old factories are not so easy to modernize. In fact, let a product communicate with others and with the factory is not enough; factories that are able to understand are the real missing part.

The second gap comes from the match between "Improve quality and added value of the product" and "Complexity vs usability". In this case, CPS ability to improve quality and value added of the products is limited by their intrinsic increasing complexity.

Table 2. Data-based improved products - Gaps

\begin{tabular}{|l|l|l|}
\hline \multirow{2}{*}{ Data-based improved products } & \multicolumn{2}{|c|}{ Obstacles } \\
\cline { 2 - 3 } & Complexity vs usability & $\begin{array}{l}\text { Communication problems } \\
\text { - smart products vs old } \\
\text { factories }\end{array}$ \\
\hline
\end{tabular}




\begin{tabular}{|c|c|c|c|}
\hline \multirow{4}{*}{ 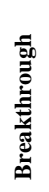 } & Data-driven product use/maintenance (MoL) & & 2 \\
\hline & Data-driving processes & & \\
\hline & $\begin{array}{l}\text { Facts and Feedback based design and pro- } \\
\text { duction }\end{array}$ & & \\
\hline & $\begin{array}{l}\text { Improved quality and added value of the } \\
\text { product }\end{array}$ & 3 & \\
\hline
\end{tabular}

\section{Cluster 3: Closed-loop manufacturing}

Through the crossed analysis of breakthrough and obstacle sub-clusters, two main gaps emerge (see Table 3). CPS could facilitate communication within and beyond the factory, allowing people to take decisions in a decentralized way. However, data security, privacy and safety problems have a high impact on the achievement of these benefits. In fact, they have been selected as primary cause of the missing implementation of decentralized decision systems. The second gap shows that integration and interoperability issues affect the potential benefits of horizontal and vertical integration. In other words, a rapid integration enabled by ubiquitous communication and integration infrastructure enabling the closed-loop manufacturing cannot be obtained mainly due to difficulty on realizing interoperable systems. Other problems related to this topic are the value chain technological fragmentation and the data security, privacy and safety.

Table 3. Closed-loop manufacturing - Gaps

\begin{tabular}{|l|l|l|l|}
\hline \multicolumn{2}{|c|}{ Closed-loop manufacturing } & \multicolumn{2}{c|}{ Obstacles } \\
\cline { 3 - 4 } \multicolumn{2}{|c|}{$\begin{array}{l}\text { Integration and in- } \\
\text { teroperability issues }\end{array}$} & $\begin{array}{l}\text { Security, privacy and } \\
\text { safety }\end{array}$ \\
\hline \multirow{3}{*}{} & Autonomous decentralized decisions & & 4 \\
\cline { 2 - 4 } & Customer in the loop & & \\
\cline { 2 - 4 } & Flexible, resilient and agile value chain & & \\
\cline { 2 - 4 } & Horizontal and vertical integration & & \\
\cline { 2 - 4 } & Real time control from data availability & & \\
\hline
\end{tabular}

\section{Cluster 4: Cyberized Plant / "Plug and Produce"}

From the analysis of the breakthroughs and obstacles included in this Cluster, a key topic needing further studies is related to the benefits from the plant flexibility such as the ability to enable the information sharing between devices and the self-reconfiguration of the stations. The Cyber-physical flexibility enables the rapid intervention at shop floor level by means of augmented reality solutions. These opportunities are hard to be reached mainly due to difficulties in terms of time, effort and costs of transforming the current production systems in a cyberized environment as well as limits related to the uncertain performance reliability and availability of the systems. The same obstacles also affects the prediction and forecasting of the plant behaviour and its related benefits without being a specific gap. Another area requiring further research is related to the system and process reconfigurability. In fact, to obtain a fully reconfiguration of the production environment, some characteristics (layout, working conditions, operators activity) of the environment have to be changed, and this could create potential risks for workers and system security. 
Table 4. Cyberized plant / "Plug \& Produce" - Gaps

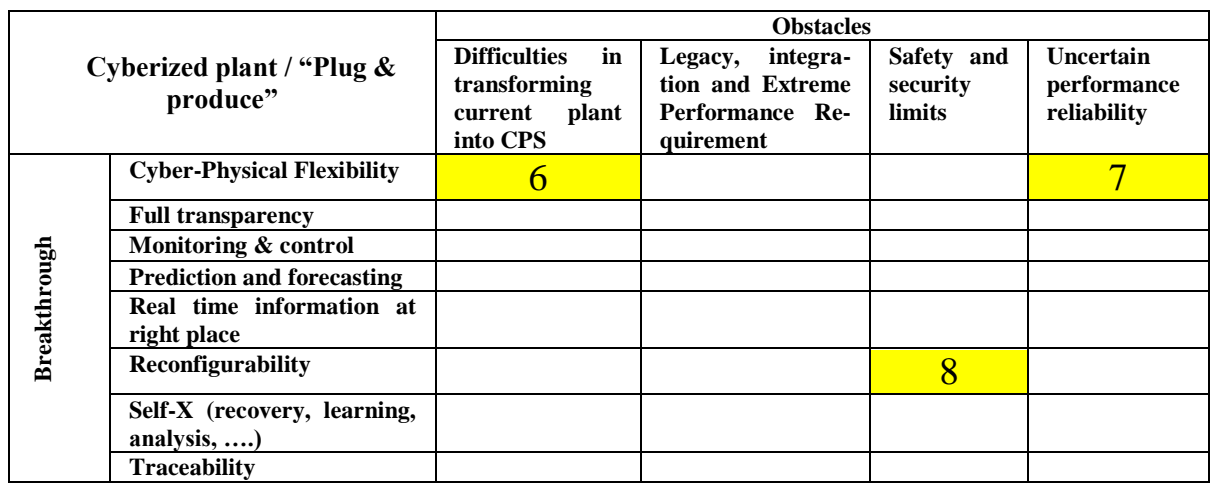

\section{Cluster 5: Next step production efficiency}

Regarding the $5^{\text {th }}$ cluster identified, the "Legacy and old technologies CPS migration" obstacle represents the main limit to the CPS ability to improve energy efficiency and to optimize plant operations. This is because it makes difficult to find solutions for an efficient and cheap integration of CPS in brownfield plants.

Table 5. Next step production efficiency - Gaps

\begin{tabular}{|l|l|l|}
\hline \multicolumn{2}{|c|}{ Next step production efficiency } & \multicolumn{1}{c|}{ Obstacle } \\
\cline { 3 - 3 } \multicolumn{4}{|c|}{} & Allow small lot sizes & Legacy and old technologies CPS migration \\
\cline { 2 - 3 } & Cyber-physical production efficiency & \\
\cline { 2 - 3 } & Improve energy efficiency & \\
\cline { 2 - 3 } & Plant operations optimization & \\
\cline { 2 - 3 } & Faster engineering process & \\
\cline { 2 - 3 } & Flexible equipment, agile processes & \\
\cline { 2 - 3 } & Improve logistics processes (reduce failure, invento- & \\
ries,) & \\
\cline { 2 - 3 } & Predictive problem solving & \\
\cline { 2 - 3 } & Real and digital fusion & \\
\cline { 2 - 3 } & Self-learning zero defect manufacturing & \\
\hline
\end{tabular}

\section{Cluster 6: Digital ergonomics}

The identified gaps concerning this Cluster are reported in Table 6. The first one sees the advantages for workers, which are facilitated in doing their job and take decisions thanks to the human automation co-working, limited by problems related to their safety and by the lack of new regulations in terms of security; while the second concerns the system over-functionalities that could limit the reduction of management complexity.

Table 6. Digital ergonomics - Gaps

\begin{tabular}{|c|c|c|c|c|c|}
\hline \multirow[b]{2}{*}{ Digital ergonomics } & \multicolumn{4}{|c|}{ Obstacles } & \\
\hline & $\begin{array}{l}\text { Complexity } \\
\text { (over func- } \\
\text { tionalities) }\end{array}$ & $\begin{array}{l}\text { Data se- } \\
\text { curity }\end{array}$ & \begin{tabular}{lr}
\multicolumn{2}{l}{ Human safety } \\
and & related \\
aged & regula- \\
tions &
\end{tabular} & $\begin{array}{l}\text { Lack of skilled } \\
\text { end educated } \\
\text { workforce }\end{array}$ & $\begin{array}{l}\text { Legacy } \\
\text { systems }\end{array}$ \\
\hline
\end{tabular}




\begin{tabular}{|c|c|c|c|}
\hline \multirow{3}{*}{ 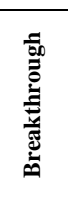 } & $\begin{array}{l}\text { Enhanced humans } \\
\text { sensing and intelli- } \\
\text { gence }\end{array}$ & & 10 \\
\hline & Factory in my pocket & & \\
\hline & $\begin{array}{l}\text { Reduced manage- } \\
\text { ment complexity }\end{array}$ & 11 & \\
\hline
\end{tabular}

\subsection{Additional findings}

Carrying out the analysis of Obstacles associated to Breakthrough executing the Gap Analysis Exercise, some other types of Obstacles have been identified as related with macro-dynamics (social, economic or technological) that this study could not expect to be addressed in a technology oriented research roadmap. Here following the above mentioned categories

Cultural, Educational and Perception: This issue can be addressed involving Schools and Universities in a significant effort to spread awareness of CPS adoption concepts in manufacturing and to bring CPS concepts outside the niche bounders of people of the specific sector.

Overestimation of costs: CPS technologies are considered "expensive" both in term of infrastructure and implementation, independently from the expected advantages.

With this respect, it should consider (especially for SME) the opportunity for supporting modernization investments.

Law, Regulations, Technology Enablers and EU Macro Economic Factors: this part regards the aspects that are beyond the technical and process perspective, like Legislation of adoption of CPS, and Liability of their utilization, both as a provider and as a utilizer

Standards and certifications: as far as standardization concerned, the definition or fostering of existing standards is definitely a point that need to be addressed as the CPS technologies are not mature enough to have defined a clear de-facto standard.

Moreover, the increasing complexity of CPS-ized products and the commercialization of products in many countries brings up the issue of product certifications for each possible market. That could represent a major effort to undertake (especially for SME with limited production volumes).

\section{Conclusions}

Output of the analysis described in this paper can be summarized in Table 7.

Table 7. Summary of Gap analysis exercise

\begin{tabular}{|c|c|c|}
\hline Cluster & Breakthrough & Gaps \\
\hline $\begin{array}{l}\text { CL } 1 \\
\text { New data-driven services } \\
\text { and business models }\end{array}$ & $\begin{array}{l}\text { Digital business ecosystems for sens- } \\
\text { ing product/services }\end{array}$ & 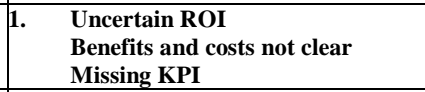 \\
\hline CL 2 & $\begin{array}{l}\text { Data-driven products use/maintenance } \\
\text { (MoL) }\end{array}$ & 2. $\begin{array}{l}\text { Communication problems - smart } \\
\text { products vs old factories }\end{array}$ \\
\hline
\end{tabular}




\begin{tabular}{|c|c|c|c|}
\hline $\begin{array}{l}\text { Data-based improved prod- } \\
\text { ucts }\end{array}$ & $\begin{array}{l}\text { Improve quality and added value of } \\
\text { product }\end{array}$ & 3. & Complexity vs usability \\
\hline \multirow{2}{*}{$\begin{array}{l}\text { CL } 3 \\
\text { Closed-loop manufacturing }\end{array}$} & Autonomous decentralized decisions & 4. & Data Security and privacy \\
\hline & Horizontal and vertical integration & 5. & Integration and interoperability \\
\hline \multirow{3}{*}{$\begin{array}{l}\text { CL } 4 \\
\text { Cyberized plant / "Plug \& } \\
\text { Produce" }\end{array}$} & Cyber-physical flexibility & & $\begin{array}{l}\text { Difficulties in transforming current } \\
\text { plant into CPS based systems }\end{array}$ \\
\hline & Cyber-physical flexibility & 7. & Uncertain performance reliability \\
\hline & Reconfigurability & 8. & Safety and security limits \\
\hline \multirow{2}{*}{$\begin{array}{l}\text { CL } 5 \\
\text { Next step production effi- } \\
\text { ciency }\end{array}$} & Improve energy efficiency & \multirow[t]{2}{*}{9.} & \multirow{2}{*}{$\begin{array}{l}\text { Legacy and old technologies CPS mi- } \\
\text { gration }\end{array}$} \\
\hline & Plant operations optimization & & \\
\hline \multirow{2}{*}{$\begin{array}{l}\text { CL } 6 \\
\text { Digital Ergonomics }\end{array}$} & $\begin{array}{l}\text { Enhanced humans sensing and intelli- } \\
\text { gence }\end{array}$ & 10. & $\begin{array}{l}\text { Workers role and related aged regu- } \\
\text { lations }\end{array}$ \\
\hline & Reduce management complexity & 11. & $\begin{array}{l}\text { Management Complexity (over func- } \\
\text { tionalities) }\end{array}$ \\
\hline
\end{tabular}

Here following it is listed a short description of the 11 identified Gaps:

Uncertain ROI - Benefits and costs not clear- Missing KPI: In this new context, it is crucial to provide decision makers of tools for forecasting and monitoring benefits and risks. The challenge is the definition of simple and reactive tools and methodologies, supported by a strong technology able to provide information about the value of the investments.

Communication \& Coexistence - smart products vs old factories: The problem arises from the fact that these products are manufactured in "classical" environment, not designed for supporting "smart" products. The question is how to evolve the production environment to support the fast evolution of the complex and poly morphed (hard components, software, services, eco-sustainability, etc.) products.

Complexity vs usability: CPS enabling technologies and CPS related process add a new level of complexity, not always perceived as part of the "core business". From that comes the need to a seamless, easy-to-use CPS environment to be deployed in transparent way in the factory and along the Value Chain.

Data Security and Privacy: CPS is dealing with big amount of data. A complete new scale of magnitude of complexity arises from data management and sharing to ensure that data are available, protected and reserved.

Integration and interoperability: It is necessary to interpreter the integration and interoperability along a much broader range in term of geographical spread, but also as time horizon as CPS diffusion is challenging a new approach that involve a great number of players, stakeholders and components

Difficulties in transforming current plant into CPS based systems: Smart products are going to be produced in existing facilities. What are the criteria to define an evolutionary path for these infrastructures without impacting the process performances and efficiency? It is required both a technological, but even methodological approach to such challenge.

Uncertain performance reliability: Although CPS approach promises a huge increase in potential performance of the systems, it raises the question about the reliability of the overall systems and the implication of a failure or a degradation of their functions. 
Safety and security limits: It is crucial to clearly identify collaboration pattern among human operator and automated systems in order to avoid possible problem for safety on the shop floor, as more functions and operations are going to be delegated to such autonomous systems.

Legacy and old technologies migration to CPS: At the level of the basic monitoring, actuation and cooperation level a dramatic change of the technologies or at least their encapsulation is required to support CPS approach.

Workers role and related aged regulations: It is clear that the human factor can contribute to make more flexible the CPS system or support it in case of problems, but it is not clear how they can interact, with which interfaces. This is a social megatrend that are challenging the profile of the classical "blue collar", both from the age perspective and for the knowledge of the workers.

Management Complexity (over functionalities): There is a risk that the complexity of the viewable context depletes the quality of the available information to support the right choice. In fact, it is important that the huge amount information provided by CPS are made available when needed to whom is actually concerned and with the appropriate context to avoid wrong decisions

The identification of the Gaps to overcome in order to achieve the envisaged Breakthroughs in CPS adoption in manufacturing contexts is a key step for the definition and the validation of the Research Priorities constituting the Research Roadmap for adoption of CPS in Manufacturing, as carried out in sCorPiuS project.

\section{Acknowledgment}

sCorPiuS is supported by the European Union's H2020 Framework Program, under grant agreement $n^{\circ} 636906$

\section{$5 \quad$ References}

1. Gunes, V., Peter, S., Givargis, T., \& Vahid, F. (2014). A survey on concepts, applications, and challenges in cyber-physical systems. KSII Transactions on Internet and Information Systems, 8(12), 4242-4268.

2. Hu, F., Lu, Y., Vasilakos, A. V, Hao, Q., Ma, R., Patil, Y., Xiong, N. (2015). Robust CyberPhysical Systems: Concept, models, and implementation. Future Generation Computer Systems

3. Lee, E. a. (2006). Cyber-Physical Systems - Are Computing Foundations Adequate? October, 1,1-9.

4. Lee, E. a. (2008). Cyber Physical Systems : Design Challenges. Proceedings of the 11th IEEE International Symposium on Object Oriented Real-Time Distributed Computing (ISORC '08), 363-369.

5. Lee, J., Bagheri, B., \& Kao, H. A. (2015). A Cyber-Physical Systems architecture for Industry 4.0-based manufacturing systems. Manufacturing Letters, 3, 18-23.

6. Oettinger, G. (2015). Europe's future is digital. Hannover https://ec.europa.eu/commission/2014-2019/oettinger/announcements/

7. sCorPiuS State of the art on Cyber-Physical Systems - March 2016

8. sCorPiuS Vision white paper - March 2016

9. Wang, L., Törngren, M., \& Onori, M. (2015). Current status and advancement of cyberphysical systems in manufacturing. Journal of Manufacturing Systems. 
